\section{Long Cervix.}

The uterus is long and loose. The cervix appears first at the vulva and the vaginal roof is inverted from above downwards round the elongated cervix. There is no cystocele. This is the form of prolapse seen in virgins and nulliparæ as well as in parous women. (Fig. 1.)

Treatment.-Excise the front half of the vaginal roof together with the cervix, leaving the uterus three inches long. Repair the perineum.

\section{Cystocele.}

The anterior vaginal wall is everted from below upwards as in true prolapsus, but the uterus retains its normal position. Seen in parous women with defective perineum, but not in virgins and nulliparæ.

Treatment.-Anterior colporrhaphy and perineal repair.

\section{Reotocele.}

The posterior vaginal wall is everted from below upwards with the anterior rectal wall adherent to it. Seen in parous women with torn perineum, but not in virgins or nulliparæ.

Treatment.-Remove most of the posterior vaginal wall and repair the perineum. The best method is Professor

FIG. 3.

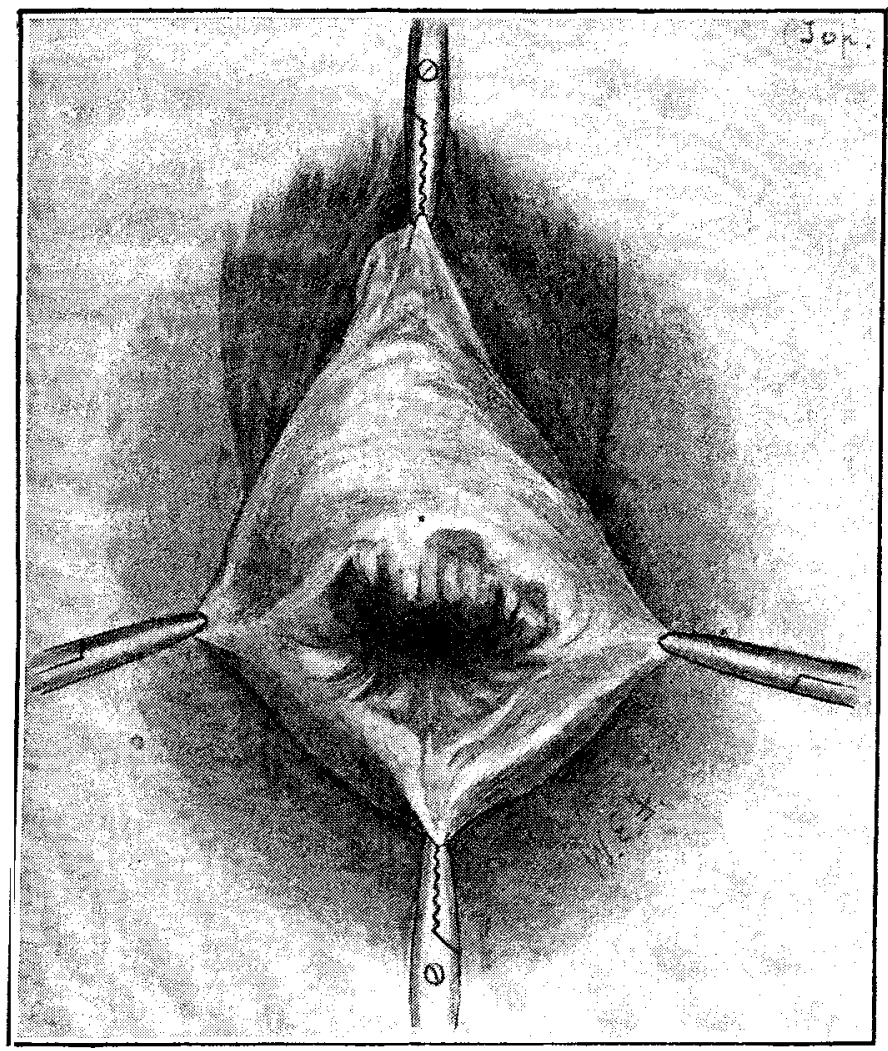

Case of true prolapsus prepared for operation by the writer's method. The incision will join the four pairs of forceps, thus enclosing the removed in one piece. (Drawing from photograph by Dr. A.W. Mather.)

A. Donald's colpo-perineorrhaphy, which is done from above downwards so as to combine the two operations. ${ }^{2}$

It is hardly necessary to say that the four forms of prolapse occur in various combinations. Thus rectocele may be seen alone, with cystocele, with true prolapsus, or with long cervix and vaginal inversion.

Manchester.

2 Ibid., March, 1908.

CoRnish CheEse.-Mr. J. F. Blackshaw, of the Board of Agriculture, recently gave an interesting address to the students at the Cornwall Cheese School, Lelant. He stated that cheese could be made anywhere in Cornwall if the maker had reasonable knowledge and took ordinary precautions with regard to the cleanliness of milk. In each gallon of milk $1 \mathrm{lb}$. to $11 \mathrm{l}$ lb. of cheese was obtained by some of the students, but it teok about $2 \frac{1}{2}$ gallons of milk to make $1 \mathrm{lb}$. of butter. Consequently they would be doing more good to win the war by making cheese than by making butter. About 80,000 cows and heifers in milk were kept in Cornwall, and if 80 per cent. of the milk in Devon and Cornwall was made into cheese it would go a long way towards supplying food for the British army.

\section{A FACTOR IN THE TREATMENT OF HEAD INJURIES AND ALLIED CONDITIONS.}

By T. E. HARWOOD, B.A. Oxon., M.B., Сн.B. EdiN., RESIDENT OPHTHALMIO OFFICGR, THE KING GEORGE HOSPITAL, S.E.

CRILE has shown experimentally that a similar clinical condition with essentially similar pathological appearances in the brain may arise from four different causes : (1) Any exhausting peripheral or central stimulus ; (2) cerebral anæmia; (3) psychic causes; (4) poisons, organic and inorganic. An example of the acute phase of this general condition is sometimes seen at or soon after a surgical operation, while the "neurasthenia" that follows a head injury or so-called shell shock represents a more chronic phase. The neurasthenia that follows a head injury is probably the purest of all neurasthenic conditions, in that it may arise instantaneously in a perfectly healthy person from a single cause, though later on other factors may, and probably usually do, help to maintain and even exaggerate it. The existence of a head injury would appear to be too apt to be regarded as per se explaining everything that follows, and the sufferer is free from the stigma which too often attaches to the patient with shell shock, whereas apart from the actual injury and its direct consequences the two are in the same position but have reached it by two different routes.

The living body may be compared to an electrical system, and neurasthenia, in the widest sense of the term, to the effects on such a system of an inefficient battery. Apart from the actual injury and its direct consequences, the treatment is concerned with what Sir James Goodhart calls "watts, ampères and volts of nervous energy." The battery must be maintained and strengthened, and as little work put upon it as possible, while the patient's vicissitudes make an interesting study in the light of Crile's experiments.

Asthenopia exists at first in almost all these cases, and the application to them of Weir-Mitchell's dictum that neurasthenics do well unless they have asthenopia is that they do well unless they have persistent asthenopia. While he is in bed the patient's eyes are one of the chief sources of peripheral stimulation, and almost the only organs of his body upon which any constant voluntary effort falls. At first the mere stimulus of light may be intolerable to him, and he lies as far as may be with his eyes shut. If he opens them, blurred and ill-fused images increase his headache, giddiness, and nausea. Apart from an actual lesion of the eyes themselves or their nerve-supply, the visual acuity, even at this early stage, depends mainly on the refractive error. The reason why the images are blurred is chiefly because in his weakened state the neuro-muscular effort necessary to correct his refractive errors and give him clear images is too much for him; in other words, his ocular compensation has broken down. We learn to use our eyes in babyhood, and do not realise the extent of the effort necessary to maintain this compensation. More than this, the child can suppress the image formed by one eye, and after a shock or debilitating illness not infrequently protects himself by ignoring the more blurred image and allowing the eye producing it to wander at its own sweet will. This condition goes on until either he becomes strong enough to maintain the compensation of both eyes, or the task is rendered easier for him by glasses which give him two clear images. The adult is in no such fortunate position. With him binocular vision has usually become an ingrained habit, and he cannot suppress the image formed by either eye. If his compensation breaks down he has to deal with two blurred images, and blurred images are exceedingly difficult to fuse, whereas clear images are probably more easily fused than not. The result is that such a patient either has diplopia or is on the verge of it, and there is a constant effort going on involving three groups of musclesthose concerned with the correction of the refractive error of each eye, mainly, of course, the ciliary muscle, and those concerned with the maintenance of the parallelism of the visual axes. It is doubtful whether a pure paresis of an external ocular muscle ever occurs without a previous paresis of the ciliary muscle, and the treatment of 
a paralytic as well as of a concomitant squint lies in the correction of the refractive errors so as to produce two easily fusible images. Nature is apt to treat conditions favouring diplopia by the development of a ptosis. I was recently asked to report on a case of diplopia and recorded the glasses that gave perfect binocular vision, but was told that the information required was which muscle was affected.

Suppose a patient who was in the habit of walking ten miles a day without conscious effort and probably with great benefit, suddenly got a hernia cerebri ; no sane medical man would dream of allowing him to attempt his usual walk immediately after his accident. Yet a not dissimilar thing is done habitually by allowing these patients to struggle with the difficulties of binocular vision. If anyone doubts the effort involved in distant vision, he has only to go, say, to the Strand on a sunny summer day and study the different varieties of the frontal wrinkles of the passers-by and the mechanism of their production. He will then realise what this effort may mean to a patient whose nervous energy is at its lowest ebb. If a patient definitely complains of constant diplopia he is almost sure to have one eye covered, but all these patients are on the verge of diplopia and most of them would benefit to a surprising extent by the covering of the eye which produces the more blurred image. This is only an imitation of nature's methods, and automatically cuts out two of the three groups of muscles involved, besides diminishing the sources of peripheral stimulation. Many can see clearly in the distance with one eye when they cannot with two; many can read with one eye but not with two, and there is much relief both to headache and giddiness ; care must be taken to prevent too much reading. It is essential to find out which is the right eye to cover, and it should be covered with an interval of a few hours every four or five days until the patient is strong enough to deal with both eyes. When a patient is wearing a head bandage, it should be made to include the more unsound eye; in other cases a comfortable shade should be used. This method is applicable not only to head injuries but to other acute forms of neurasthenia. It has been said that it will be generations before the value of Weir-Mitchell's discoveries in this direction is fully recognised.

For the observation of the frequency of diplopia in these cases at one period or another $I$ am indebted to DeputySurgeon-General H. W. G. Doyne, R.N.

\section{A NOTE ON SPINAL ANASSTHESIA. ${ }^{1}$}

BY S. B. GADGIL, F.R.C.S. ENG., LIEUTENANT, I.M.S.

$I_{T}$ is very surprising that notwithstanding the fact that spinal anæsthesia was introduced into England by the able advocacy of the late Lieutenant-Colonel $A$. E. Barker, for the last ten years it has been adopted only by a minority of surgeons in civil practice and by an even lesser number in military practice. I have inquired from different medical men on the subject, and I would like to offer some explanation as to why people feel shy about using this kind of anæsthesia. I propose also to make a few suggestions and invite discussion from those who are experienced in its use. My experience is based on 500 cases, some treated abroad, but most of them in London.

I may summarise the reasons for non-success in the use of the method of anæsthesia in the following way:-

1. Diffoulty in entering the spinal oanal.-This may be due either to nervousness on the part of operators or on that of their patients, whose confidence they have failed to win and who consequently do not keep steady at the time they feel the prick of the needle.

2. The position in which the patient is placed at the time of introduotion of the needle. - There are two positions in which the needle may be introduced. In the first the patient is required to bend forward while sitting at the end of a table; in the second he lies on one side, always, of course, in fully bent position. I have found it more difficult to introduce the needle into the spinal canal when the patient lies in this second position; the first is, in my opinion, the more convenient.

1 A paper read at a clinical meeting held at a general hospital on Feb. 10th, 1916.
3. Position after the ancesthetve is antruduoed. - I think that after the injection of the drug the patient is kept with his back propped up too high from the horizontal.

4. Amount of drug injeoted.-The amount of stovaine injected is, in my opinion, generally not sufficient.

5. The fear of collapse.-This, I think, unnerves the surgeon because he is aware that the patient is watching his actions with anxiety.

My suggestions to counteract these defects are :-

1. Do not be disappointed if you do not get into the spinal canal at the first attempt; difficulty in this matter is more common than is generally acknowledged.

2. For the novice the position of getting the patient to sit at the end of the table and to stoop over is better than the one of lying down on the side; also in the fully bent position, as stated before. (a) Always see that the lumbar spines are quite prominent before introducing the needle. (b) Puncture at the upper margin of any of the lumbar vertebræ from the second to the fourth. (c) Keep the point of the needle absolutely in the middle line and the whole needle perpendicular to the skin. (d) Do not follow the text-book advice, which is to insert the needle a little away from the middle line a little upwards and inwards. In practice I have found that the canal is often missed in following this text-book advice.

3. I always give a full ampoule of the stovaine and glucose solution, which is equivalent to a grain of stovaine, in all adult cases. I have never had any bad effects which I could attribute to a big dose. This full dose does away with the necessity of shaking gently the patient by making him sit and lie down a dozen times for diffusion of the drug, as I have seen done.

4. In some cases when operating only on one side of the body I have found it very useful to introduce the drug when the patient is lying on the side to be operated upon, even when the needle has been introduced while the patient is sitting at the end of the table in a stooping position. I will make this statement more explicit. Say I want to operate on the left knee. I make the patient sit at the end of the table in a stooping position, I introduce the needle into the canal, and when the needle is in, as shown by the escape of the cerebro-spinal fluid, I gently lay the patient on his left side before $I$ introduce the drug. He lies in that position for a minute or two and is then ready for the operation, so that I put him on his back comfortably before starting.

5. I never use this anæsthetic for any operation above the level of the umbilicus. It takes about ten minutes for anæsthesia to spread from the trochanter to the umbilicus, while for rectal operations the effect is immediate.

6. It is unnecessary to test the sensation before starting operation; though protopathic sensibility is lost, epicritic sensation remains for $\approx$ longer time, and the patient says he feels pain while he is only feeling a light touch.

7. Never introduce the drug unless the cerebro-spinal fluid is seen escaping freely.

8. When operating on abdominal cases or on any very nervous individual I give a hypodermic injection of morphine gr. $\frac{x}{4}$, atropine gr. $1 / 100$, and hyoscine $1 / 100$, three-quarters of an hour before operation. The patient generally remains asleep during the whole course of the operation.

9. Do not be nervous about the position of the head. Keep the back rest about $30^{\circ}$ from the horizontal. This height is quite sufficient. I have seen patients propped up to about $45^{\circ}$ or more from the horizontal. The anxesthetic does not diffuse rapidly and the blame for non-success of this anæsthetic is attributed to the unreliability of the drug.

10. When a patient shows signs of collapse, which are paleness, nausea, vomiting, and cold perspiration, do not be perturbed-leave him as he is for the moment, and (1) give him at once liquor strychninæ min. $\nabla$. hypodermically; (2) raise both legs up in the air, trying to meet the head, as used to be done in order to stretch the sciatic nerves in the old-fashioned way without an operation; and (3) put with the forearms great pressure over the abdomen for five minutes or more. Generally the operation may then be continued within ten minutes.

11. Headache is the only after-result I have met. I tell the patients that they would be quite well next day and I give gr. $x$. of aspirin as a placebo. 